\title{
FORMAC̣ÃO DEPROFESSORES DE CIÊNCIAS PARA O DIÁLOGO INTERCULTURAL: ANÁLISE DE UM CASO
}

\author{
Geilsa Costa Santos Baptista* \\ Janaina Gelma Alves do Nascimento**
}

RESUMO: São apresentados os resultados de um estudo qualitativo, envolvendo intervenções educacionais com uma professora de Biologia de uma escola pública no Estado da Bahia, Brasil, após a sua participação em um curso de formação continuada de professores de Ciências para o diálogo intercultural. Os dados foram coletados por meio de gravações de vídeo e analisadas pela abordagem delineada por Mortimer e Scott (2002). Os resultados mostram uma abordagem comunicativa do tipo interativa de autoridade, permitindo a alegação de que essa professora não se apropriou da proposta de diálogo intercultural apresentada durante o curso. É necessário que cursos de formação continuada de professores para o diálogo intercultural tenham lugar dentro do contexto e realidades das escolas onde os professores participantes trabalham para garantir-lhes experiências mais próximas e prolongadas entre o meio acadêmico e escolar e, por conseguinte, mudanças nas suas práticas pedagógicas neste sentido.

Palavras-chave: Formação do professor de ciências. Diálogo intercultural. Ensino de Ciências.

\section{FORMACIÓN DE PROFESORES DE CIENCIAS PARA EL DIÁLOGO INTERCULTURAL: ANÁLISIS DE UN CASO}

Resumen: Se presentan los resultados de un estudio cualitativo, que involucra intervenciones educativas con una profesora de biología de una escuela pública en el estado de Bahia, Brasil, después de su participación en un curso de formación continua para profesores de ciencias para el diálogo intercultural. Se recopilaron los datos a través de grabaciones de vídeo y se los analizaron con el enfoque delineado por Mortimer y Scott (2002). Los resultados muestran un enfoque comunicativo de tipo interactivo de autoridad que permite la afirmación de que esta profesora no se apropió de la propuesta de diálogo intercultural presentada a lo largo del curso. Es necesario que los cursos de formación continua para docentes para el diálogo intercultural sean llevados a cabo dentro del contexto y las realidades de las escuelas donde trabajan los profesores participantes, para que
*Doutora em Ensino, Filosofia e História das Ciências pela Universidade Federal da Bahia em convênio com a Universidade Estadual de Feira de Santana (UEFS. UFBA). Professora e pesquisadora no Departamento de Educação da Universidade Estadual de Feira de Santana (UEFS) e no Programa de Pós-Graduação em Ensino, Filosofia e História das Ciências (UEFS.

UFBA). Coordenadora do Grupo de Investigações em Etnobiologia e Ensino de Ciências (GIEEC-UEFS). Feira de Santana, BA - Brasil. E-mail:<geilsabaptista@gmail.com>.

* * Mestre em Ciência - Botânica pela Universidade Estadual de Feira de Santana (UEFS). Professora da Educação Municipal de Feira de Santana e do Estado da Bahia no município de Feira de Santana. Coordenadora do Currículo de Ciências e Educação Ambiental da Secretaria Municipal de Educação em Feira de Santana (BA). Pesquisadora no Grupo de Investigações em Etnobiologia e Ensino de Ciências (GIEEC-UEFS). Feira de Santana, BA - Brasil. E-mail:<janaina.bot@hotmail.com>. 
se les permitan experiencias más estrechas y prolongadas entre el mundo académico y la escuela, y, consecuentemente, cambios en sus prácticas pedagógicas en ese sentido.

Palabras clave: Formación del profesor de ciencias. Diálogo intercultural. Enseñanza de Ciencias.

\section{SCIENCE'S TEACHERS TRAINING FOR INTERCULTURAL DIALOGUE: A CASE}

\section{ANALYSIS}

ABSTRACT: This paper presents the results of a qualitative study, involving educational interventions with a Biology's teacher in a public school of the Bahia state, Brazil, after her participation in a continuing training course for Science teachers for intercultural dialogue. Data collected through video recordings and analyzed with the approach designed by Mortimer and Scott (2002). The results show a communicative approach of interactive type of authority allowing the claim that this teacher did not appropriated the proposal of intercultural dialogue presented during the course. It is necessary to carry out continuous teacher training courses for intercultural dialogue within the context and realities of schools where participating teachers work to allow them closer and more prolonged work experiences between academia and school and, consequently, to change their pedagogical practices in this way.

Keywords: Training of science teachers. Intercultural dialogue. Science education. 


\section{INTRODUÇÃO}

A formação de professores tem sido cada vez mais tomada como objeto de estudo por pesquisadores da área de educação (NÓVOA, 1992; MALDANER, 2000; TARDIF, 2002; SILVA; CHAVES, 2009). Essas pesquisas ressaltam a importância da superação da racionalidade técnica, que forma o professor para a ação mecânica no ensino, destacando a necessidade de formar professores para a racionalidade prática. Nesta perspectiva, o professor deixará de ser um mero executor de tarefas para tornar-se reflexivo e investigador na sala de aula (NÓVOA, 1992). A reflexão, segundo Schön (1992), está intimamente relacionada com a investigação. $\mathrm{O}$ professor investigador questiona sua prática e, com base nesse questionamento, reflete e aprimora as suas atividades pedagógicas. A investigação por parte dos professores contribui para a reflexão, e vice-versa, bem como para a construção de uma forma pessoal de conhecer e de uma progressão dos seus conhecimentos (SCHÖN, 1992).

No ensino de Ciências, a ação mecânica que forma o professor está associada à mera transmissão de conteúdos científicos, dissociados de contextos e significados para os estudantes. Uma prática pedagógica cientificista, resultante de uma formação docente, seja ela inicial e/ou continuada, que tem na ciência a única fonte legítima de saberes válidos para a humanidade, devendo, portanto, ser ensinada para todos os povos autoritariamente, sem abrir espaços para diálogos com outras culturas que se fazem presentes nas salas de aula por meio dos estudantes.

Desta realidade, entende-se que a reflexão e a investigação nos cursos de formação de professores de Ciências devem envolver questões epistemológicas sobre a natureza da ciência e isto porque, concordando com Vilela-Ribeiro e Benite (2009), as concepções que os professores possuem sobre a natureza da ciência influenciam significativamente na forma como eles ensinam a ciência e decidem questões nas salas de aula. Por natureza da ciência entende-se a epistemologia da ciência, ou o conjunto de valores e de pressupostos inerentes ao desenvolvimento do conhecimento científico (LEDERMAN, 1992), incluindo aí o modo como os cientistas atuam como grupo social em determinadas épocas, os seus objetivos, influências sociais, condicionantes, limites, etc. (CARVALHO, 2002). A ciência, para Aikenhead (2001), pode ser pensada como uma cultura, constituída social e historicamente, que envolve um conjunto de teorias e práticas, de atividades, ideias, hábitos, normas, valores, etc., que são compartilhados pela comunidade científica.

A reflexão epistemológica por parte dos professores de Ciências, segundo Apostolou e Koulaidis (2010), contribui para que eles desenvolvam uma visão adequada sobre a ciência que ensinam e, consequentemente, será possível investigar a sua prática pedagógica tornando-a mais apropriada para que os estudantes também compreendam a natureza da ciência que estão estudando. Além disto, poderá contribuir para a compreensão de como a ciência pode ser demarcada com relação aos outros modos de conhecer (COBERN; LOVING, 2001; BELL; LEDERMAN, 2003; TURGUT, 2011), o que é particularmente relevante para o ensino de ciência que pretenda o abandono do cientificismo em prol do estabelecimento de diálogos interculturais. Especificamente, através de diálogo que possa ser estabelecido entre os conhecimentos e práticas da ciência, enquanto 
atividade cultural, e os conhecimentos e práticas dos meios socioculturais dos estudantes. Cumpre enfatizar que os pressupostos de interculturalidade evocados neste trabalho têm origem no entendimento de que além da ciência ocidental existem inúmeros modos de produção de conhecimentos sobre o mundo natural, que são válidos nos seus contextos de origem e de aplicabilidade, e que muito podem contribuir para os avanços científicos, e vice-versa (AIKENHEAD, 2001; COBERN E LOVING, 2001; SANTOS e MENESES, 2010). Para Santos e Meneses (2010) trata-se de uma posição contrária ao eurocentrismo e monopólio da ciência ocidental, que destruiu algumas formas de saber locais, levando-os à inferiorização em nome dos desígnios do colonialismo. Trata-se, pois, de propor um pluralismo epistemológico que reconheça a existência de variadas visões de mundo que contribuam para o alargamento dos horizontes de saberes, experiências e práticas (SANTOS e MENESES, 2010).

Porque através do diálogo entre saberes inerentes à cultura da ciência e à cultura do estudante o professor gerará oportunidades para argumentações que poderão aproximar os saberes científicos aos saberes culturais dos sujeitos envolvidos, seja em termos de semelhanças e/ou de diferenças (BAPTISTA, 2007). A argumentação no ensino de Ciências consiste da externalização dos conhecimentos e das suas epistemologias por parte dos interlocutores (MENDONÇA; JUSTI, 2013) que estão envolvidos em relações dialógicas. Nessas relações ocorrem negociação de significados, pois há o encontro entre diferentes perspectivas culturais e, por conseguinte, o crescimento mútuo entre elas (MORTIMER; SCOT'T, 2002).

Neste artigo são apresentados os resultados de uma pesquisaqueenvolveu intervenções pedagógicas realizadas por uma professora de Biologia da rede pública de ensino do estado da Bahia, Brasil, logo após a sua participação num curso de formação continuada de professores de Ciências para o diálogo intercultural, oferecido pela Universidade Estadual de Feira de Santana (UEFS), Bahia, Brasil. A pesquisa partiu do seguinte questionamento: - É possível que um professor de ciência realize o diálogo intercultural nas suas aulas logo após a sua participação num curso de formação continuada de professores voltado para esta finalidade? O objetivo deste trabalho é, portanto, explorar uma resposta para este quetionamento e, com base nisto, propor uma alternativa para a formação continuada do professor de ciências no tocante ao diálogo intercultural.

Embora este estudo tenha sido realizado no contexto do Brasil, espera-se que seus resultados sirvam para ampliar as discussões na literatura da área voltada para a formação de professores e sua relação com o ensino das ciências de outros países, particularmente no que diz respeito à preparação destes profissionais para a realização de diálogos entre o conhecimento científico e outros conhecimentos culturais presentes nas salas de aula. Este estudo pode ser relevante, por exemplo, para os países onde existemescolas com alta diversidade étnica, cultural, religiosa, nas quais se torna cada vez mais necessária uma formação docente adequada para relacionar-se com a diversidade de culturas e, ao mesmo tempo, ensinar Ciências. Sobre isto é importante considerar que a imigração tem sido um fator frequente ao redor do mundo, dados os avanços da globalização e facilitação de deslocamento humano por diversas razões. Esta expectativa tem amparo nos argumentos de 
Stake (1995), para o qual um estudo de caso pode ter uma validade externaquando os seus resultados podem ser generalizados para outros casos cujas realidades sejam similares, permitindo, assim, uma compreensão mais ampla de um fenômeno particular, população ou condição.

Finalmente, espera-se que os resultados desta pesquisa também possam contribuir para a prática pedagógica dos professores de Ciências nas salas de aula, para que ampliem as suas reflexões sobre a maneira como ensinam, gerando oportunidades para que os estudantes compreendam ${ }^{1}$ a ciência a partir de diálogos com os saberes culturais que são inerentes aos seus meios sociais.

\section{METODOLOGIA}

\section{Abordagem, sujeitos participantese questões éticas}

O estudo, ora descrito,teve abordagem qualitativa baseada no estudo de caso e envolveu intervenções pedagógicas realizadas por uma das professoras de Biologia (segunda autora deste artigo) que participaram de um curso de formação continuada para professores de Ciências da rede pública de ensino do estado da Bahia, Brasil, para o diálogo intercultural nas salas de aula de Ciências. A coleta de dados se deu sobre dados transcritos da videogravação dessas intervenções (CARVALHO, 2006) e as análises aconteceram por meio da ferramenta proposta por Mortimer e Scott (2002). A seguir, serão descritos os procedimentos do curso, da coleta e análise dos dados.

Oreferido curso de formação de professores aconteceu em 2009 e foi orientado pela primeira autora deste artigo, como proposta de extensão universitária pela UEFS. Quatorze professoras realizaram as suas inscrições no referido curso, com idades que variaram entre 28 e 45 anos. Essas professoras ministravam aulas de Ciências Naturais (do 60 ao 90 ano da Educação Fundamental, para estudantes com idades entre 11 e 14 anos) e de Biologia (do 10 ao 30 ano da Educação Média, para estudantes com idades entre 15 e 17 anos). Por questões éticas, todas essas professoras assinaram um Termo de Consentimento Livre e Esclarecido (TCLE), conforme a resolução vigente no Brasil na época, a Resolução 196/96, do Ministério da Saúde (BRASIL, 2003).

\section{0 curso de formação continuada de professores de Ciências e a coleta de dados}

O curso aconteceu no espaço físico da UEFS, localizada na cidade de Feira de Santana, Bahia, Nordeste do Brasil, a $110 \mathrm{~km}$ da cidade de Salvador, capital do estado. Teve por título Contribuições de Etnobiologia, da História e da Filosofia das Ciências para a formação do Professor de Ciências Sensível à Diversidade Cultural e amparou-se na perspectiva do trabalho colaborativo (PARRILLA; DANIELS, 2004). Partiu-se do princípio de que interações sistemáticas e orientadas durante as atividades desenvolvidas no curso seriam fundamentais para a realização de investigações e reflexões por parte dos professores e, por conseguinte, para o seu desenvolvimento cognitivo e profissional. 
A carga horária total do curso foi de 132 horas e objetivou contribuir para sensibilização de professores de Ciências quanto à diversidade cultural presente nas salas de aula através do diálogo intercultural. As abordagens teoria e prática foram interligadas, acontecendo nas salas de aula da UEFS e das escolas onde as participantes são professoras, todas localizadas no município de Feira de Santana, Bahia, Brasil.

Os seguintes temas foram centrais para o desenvolvimento teórico do curso: - A etnobiologia ${ }^{2}$, conceitos, seu objeto de estudo, procedimentos metodológicos de pesquisa e contribuições para a investigação dos saberes culturais dos estudantes ligados à natureza; - A história e a filosofia das ciências e suas contribuições para a compreensão da natureza da ciência e demarcação de saberes no ensino de Ciências; - A relevância da investigação da prática pedagógica e dos saberes culturais dos estudantes para o diálogo intercultural no ensino de Ciências. Tais temas foram trabalhados nas seguintes estratégias: - Análises de textos relacionados com a temática; - Realização de procedimentos de pesquisa da etnobiologia para investigação dos saberes culturais dos estudantes das escolas onde atuam as professoras participantes; - Produção de recursos e sequências didáticas contendo os conhecimentos culturais dos estudantes com respectivas relações de semelhanças e de diferenças com o conhecimento biológico escolar; - Intervenções no ensino de Biologia nas escolas onde atuam as professoras participantes baseadas no diálogo intercultural.

Todos os recursos e sequências didáticas construídas foram apresentados na sala de aula do curso. O objetivo foi abrir espaço para análise e discussão sobre os mesmos, de modo que fosse possível eleger aqueles considerados como sendo os melhores para serem aplicados nas salas de aula de Biologia. Tendo sido eleitos dois desses recursos e sequências didáticas, as professoras autoras foram convidadas e aceitaram livremente a aplicação desses recursos e sequências didáticas nas salas de aula onde atuam. É importante salientar que neste trabalho são apresentados apenas os resultados das intervenções pedagógicas realizadas por uma dessas duas professoras e isto pelo fato de que o curto espaço de um artigo não permitiria discussões mais ampliadas envolvendo a outra professora participante. Além disto, o estudo ora relatado constitui um estudo de caso, onde a preocupação não está na amostra, mas, sim, na descrição e compreensão de um fenômeno particular (YIN, 2003). Também é importante salientar que foi lançado o convite para a escrita deste artigo às duas professoras participantes, tendo, apenas uma,aceitado, que chamaremos aqui de professora coautora. Segundo a outra professora, a sua recusa se deu pela falta de tempo para leituras e análises do artigo em construção, dada a sua carga horária excessiva na escola onde atua como docente.

As aulas realizadas pelas duas professoras foram filmadas (CARVALHO, 2006) e a escolha desta técnica para coleta de dados se deu por acreditar que a mesma permite capturar de forma mais ampla os diferentes aspectos das interações realizadas nas salas de aula e, do mesmo modo, uma mínima interferência por parte do pesquisador (MARTINS, 2004).

Cada professora que aceitou participar cumpriu um total de quatro intervenções, subdivididas em dois momentos (aulas geminadas) que aconteceram em duas semanas seguidas. O procedimento para a filmagem das aulas consistiu da instalação de uma câmera de vídeo num dos cantos da frente das salas de aula e do posicionamento da pesquisadora no fundo dessas salas, controlando 
uma segunda câmera (CARVALHO, 2006). Nas figuras 1 é possível visualizar os posicionamentos dos estudantes, que estavam dispostos em grupos, e das câmeras nas duas salas de aulas utilizadas pela professora coautora. Foram cinco grupos de estudantes na sala de aula desta professora e ela ficou livremente transitando por todos os espaços das salas de aula.

Figura 1 - Posicionamento dos grupos de estudantes e das câmeras de filmar nas intervenções realizadas pela professora coautora.

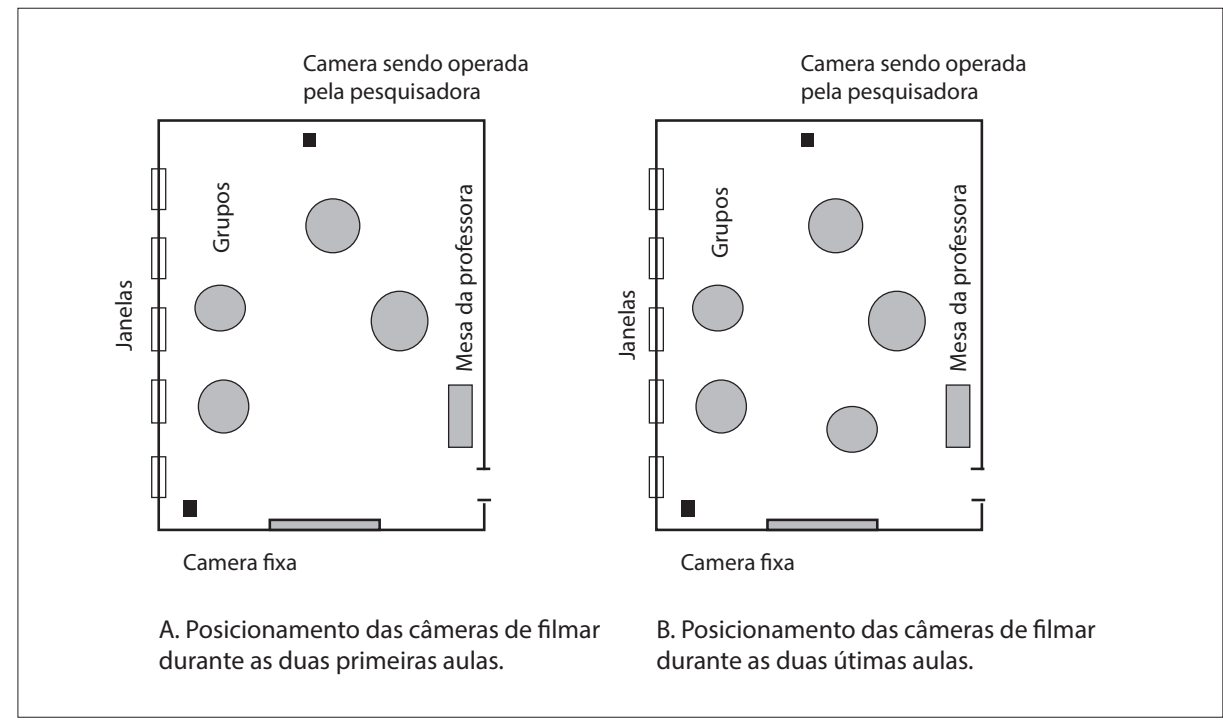

Fonte: Elaborado pela autora.

As filmagens das intervenções pedagógicas realizadas pelas professoras foram apresentadas, assistidas e discutidas livremente durante o curso na sala de aula da UEFS, entre as demais professoras participantes e a orientadora. O objetivo disto foi abrir espaços para reflexões e discussões entre os pares. Partiu-se do pressuposto de que discussões sobre as intervenções nas realidades das salas de aula permitiriam às professoras participantes a realização de reflexões sobre as suas próprias ações pedagógicas no tocante ao diálogo intercultural, considerando aí as abordagens previamente realizadas durante todo o curso de formação continuada e as suas realidades de ensino.

\section{Análise dos dados}

Após as filmagens terem sido assistidas e discutidas, elas foram transcritas para um editor de texto (CARVALHO, 2006) com o propósito de construção de mapas de eventos, isto é, esquemas das principais partes das aulas (AMARAL; MORTIMER, 2006). Segundo Amaral e Mortimer (2006), os mapas de eventos, ou mapas de atividades, constituem recortes que representam os contextos característicos das atividades desenvolvidas nas salas de aulas e contribuem para a escolha dos episódios ou eventos que permitirão as análises das interações discursivas em salas de aula. Com o intuito de garantir a privacidade dos 
estudantes, seus nomes, que foram citados nas salas de aula pela professora não são mencionados nas transcrições.

Para análise das intervenções pedagógicas foi utilizada parte da estrutura analítica indicada por Mortimer e Scott (2002), que serve para avaliar o modo como os professores interagem nas salas de aula com os alunos. Particularmente neste trabalho, o foco das análises da análise incidiu sobre o tipo de Abordagem Comunicativa exercida entre as professoras e os estudantes na sala de aula, isto é, se foi interativo ou não interativo e se dialógico ou de autoridade (MORTIMER; SCOT'T, 2002).

Para Mortimer e Scott (2002), várias são as formas pelas quais os professores interagem com os estudantes para trabalhar os conteúdos científicos e, dentre elas, está a fala. Estes autores explicam que em algumas ocasiões o professor lidera as discussões com toda a classe. Já em outras, os estudantes trabalham em pequenos grupos e o professor desloca-se entre eles, ajudando-os no desenvolvimento das atividades. Em outras ocasiões, porém, o professor faz uma série de questões e as respostas dos estudantes, na maioria das vezes, limitam-se a palavras que apenas preenchem as lacunas no discurso do professor. $\mathrm{Na}$ maioria dos casos, o professor é extremamente hábil nesse estilo de exposição, contudo, pouco espaço é aberto para que os estudantes façam ou falem algo, e muitos nunca abrem a boca (MORTIMER; SCOTT, 2002).

Mortimer e Scott (2002) identificaram quatro classes de abordagem comunicativa que são definidas por meio da caracterização do discurso entre professor e estudantes ou entre estudantes em termos de duas dimensões: 1- Discurso dialógico ou de autoridade e 2- Discurso interativo ou não interativo. $\mathrm{Na}$ dimensão dialógica, o professor dá a vez e a voz ao aluno e ocorre interanimação de ideias. Já na dimensão de autoridade, o professor considera aquilo que o aluno diz apenas do ponto de vista do discurso científico escolar, não há múltiplas vozes e interanimação de ideias.

$\mathrm{Na}$ dimensão interativo ou não interativo, o discurso Interativo é aquele que ocorre com a participação de mais de uma pessoa, e o discurso não interativo é aquele que ocorre com a participação de uma única pessoa. As duas dimensões identificadas (dialógico ou de autoridade e interativo e não interativo)podem ser combinadas para gerar quatro classes de abordagem comunicativa (Quadro 1).

Quadro 1 - As quatro classes de abordagem comunicativa geradas da combinação das dimensões dialógica ou de autoridade e interativo e não interativo.

\begin{tabular}{|c|c|c|}
\hline & INTERATIVO & NÃO INTERATIVO \\
\hline DIALÓGICO & Interativo /Dialógico & Não interativo / Dialógico \\
\hline AUTORIDADE & Interativo/de autoridade & Não interativo de autoridade \\
\hline
\end{tabular}

Fonte: Mortimer e Scott (2002).

$\mathrm{Na}$ classe Interativo/dialógico: professor e estudantes exploram ideias, formulam perguntas autênticas e oferecem, consideram e trabalham diferentes pontos de vista. Na classe Não-interativo/dialógico: o professor reconsidera, na sua fala, vários pontos 
de vista, destacando similaridades e diferenças. Na classe Interativo/de autoridade: professor geralmente conduz os estudantes por meio de uma sequência de perguntas e respostas, com o objetivo de chegar a um ponto de vista específico. Por último, a classe não-interativo/de autoridade: professor apresenta um ponto de vista específico.

Mortimer e Scott (2002) ressaltam que embora cada uma dessas quatro classes esteja relacionada ao papel do professor ao conduzir o discurso da classe, elas são aplicáveis também para caracterizar as interações que ocorrem apenas entre estudantes, como, por exemplo, em pequenos grupos.

\section{RESULTADOS E DISCUSSÕES}

Por questões de espaço neste artigo, foi selecionado apenas um dos episódios das intervenções da professora coautora (AMARAL; MORTIMER, 2006), que se deu a partir dos mapas das atividades por ela desenvolvidas. O foco das análises foi a abordagem comunicativa feita pela professora na sala de aula, isto é, se interativo ou não interativo e se dialógico ou de autoridade. A seguir, serão apresentados os mapas das atividades desenvolvidas, bem como o episódio selecionado com suas respectivas análises com base na ferramenta proposta por Mortimer e Scott (2002).

\section{Intervenções realizadas pela professora coautora: mapas das atividades, episódio selecionado e análises}

As intervenções aconteceram no dia 23 de setembro de 2009, com duração total de $59 \mathrm{~min} 48 \mathrm{~s}$, e no dia 30 de setembro de 2009, com duração total de 41 min30s. As aulas aconteceram numa turma de Biologia do segundo ano do Ensino Médio, do curso de Formação Geral do noturno, do Instituto de Educação Gastão Guimarães (IEGG), localizado na Avenida Sampaio, S/N, Centro, Feira de Santana, Bahia. Estiveram presentes quarenta e seis estudantes, entre homens e mulheres, com idades entre 22 e 28 anos. De maneira geral, esses estudantes eram agricultores e comerciantes que optaram pelo estudo noturno exatamente pela falta de tempo diurno, já que exercem as suas atividades econômicas durante o dia. No Brasil, considera-se Formação Geral o curso não profissionalizante, ou seja, que não prepara o estudante para uma profissão específica ao nível Médio de ensino.

Segundo informações obtidas junto ao Blog do Colegiado Escolar Gastão Guimarães (BCEGG, 2010), o IEGG foi inaugurado no dia $1^{\circ}$ de junho de 1927, com o nome Escola Normal de Feira de Santana. Nesta época, o IEGG atuava na formação primária e de professores e, mais tarde, em 1949, passou a oferecer cursos do ginásio e secundário sendo nomeado de Escola Normal e Colégio Estadual de Feira de Santana. Em 1962, passou a receber o nome que permanece até os dias atuais, ou seja, Instituto de Educação Gastão Guimarães. Na década de 1990 a instituição passou a integrar o Curso de Formação Geral e, assim, reduziu a oferta de vagas para o magistério. Como resultado disto, ocorreram mudanças no perfil dos estudantes, de predominantemente feminino para incorporação de uma significativa parcela do gênero masculino. Hoje, o IEGG cresceu com a heterogeneidade cultural, social, econômica e religiosa e constitui um dos maiores estabelecimentos de ensino público estadual de Feira de Santana. Classificado como instituição de porte especial, 
o IEGG pertencente à Diretoria Regional de Educação (DIREC 02), órgão da Secretaria de Educação do Estado da Bahia, com mais de três mil alunos. Funciona nos três turnos, com Ensino Médio (Formação Geral), Ensino Fundamental (60 ao 90 ano) e também a Educação de Jovens e Adultos (EJA).

As intervenções pedagógicas tiveram como temática central Pragas Agrícolas e Controle Biológico, com os seguintes conteúdos de ensino: Agricultura: conceitos, importâncias e necessidades; Insetos e seu mundo diversificado: características gerais e habitat; Pragas agrícolas: conceitos e tipos; Venenos e defensivos químicos; Controle biológico de pragas, saúde e qualidade do meio ambiente.Este tema foi escolhido por unanimidade pelas professoras participantes do curso, em virtude do fato de que elas atuam em escolas onde a maioria dos estudantes são agricultores ou filhos de agricultores e sofrem com a problemática de insetos que atacam as plantas cultivadas, tendo o ensino da biologia como coadjuvante.

Os objetivos gerais de ensino esboçados pela professora foram: - Discutir a importância e a necessidade do controle biológico de pragas agrícolas para o meio ambiente, para a saúde de agricultores e de consumidores dos produtos cultivados em lavouras; - Valorizar o trabalho agrícola a fim de contribuir com o fortalecimento da identidade dos estudantes com o meio em que vivem e minimizar a discriminação apontada pelo trabalhador do campo. A seguir, nos Quadros 2 e 3, serão apresentados os mapas dos principais eventos (atividades) ocorridos durante as intervenções realizadas pela professora coautora.

Quadro 2 - Mapa dos eventos ocorridos nas duas primeiras aulas da professora coautora no dia 23 de setembro de 2009, com duração de 59min48s

\begin{tabular}{|c|c|c|c|c|}
\hline Duração & Atividades & Temas abordados & Ações dos participantes & Comentários \\
\hline $08 \mathrm{~min} 5 \mathrm{~s}$ & $\begin{array}{l}\text { - Introdução } \\
\text { das aulas. }\end{array}$ & & $\begin{array}{l}\text { - Os estudantes } \\
\text { sentaram-se } \\
\text { organizados em grupos; } \\
\text { - A professora lembrou } \\
\text { aos estudantes que } \\
\text { as aulas constituem } \\
\text { parte de um projeto } \\
\text { desenvolvido pela } \\
\text { UEFS e apresentou a } \\
\text { pesquisadora. Também } \\
\text { lembrou a realização } \\
\text { das entrevistas que } \\
\text { participaram e informou } \\
\text { o tema da aula (pragas } \\
\text { agrícolas, veneno e } \\
\text { controle biológico); } \\
\text { - A professora } \\
\text { apresentou o objetivo } \\
\text { das intervenções e } \\
\text { distribuiu um texto } \\
\text { (material didático), } \\
\text { solicitando a sua leitura; } \\
\text { - A professora solicitou } \\
\text { a assinatura dos } \\
\text { estudantes numa lista } \\
\text { de presença. }\end{array}$ & $\begin{array}{l}\text { - Silêncio intenso } \\
\text { na sala de aula. }\end{array}$ \\
\hline
\end{tabular}




\begin{tabular}{|c|c|c|c|c|}
\hline Duração & Atividades & Temas abordados & Ações dos participantes & Comentários \\
\hline $36 \min 51 \mathrm{~s}$ & $\begin{array}{l}\text { - Leitura } \\
\text { de um texto } \\
\text { (recurso didático } \\
\text { elaborado pela } \\
\text { professora } \\
\text { coautora) e } \\
\text { discussão. } \\
\text { - Episódio 1: } \\
\text { Explorando } \\
\text { ideias sobre } \\
\text { agricultura: } \\
\text { contribuição } \\
\text { da ciência; } \\
\text { importância; } \\
\text { utilização } \\
\text { de produtos } \\
\text { químicos } \\
\text { e controle } \\
\text { biológico com } \\
\text { insetos. }\end{array}$ & $\begin{array}{l}\text { - Agricultura, } \\
\text { pragas agrícolas } \\
\text { e contribuição } \\
\text { da ciência para o } \\
\text { combate (controle } \\
\text { biológico). }\end{array}$ & $\begin{array}{l}\text { - Os estudantes leram } \\
\text { o texto de forma } \\
\text { silenciosa; } \\
\text { - A professora lançou } \\
\text { questionamentos sobre } \\
\text { entendimentos do texto; } \\
\text { - Os estudantes } \\
\text { explanaram os seus } \\
\text { entendimentos; } \\
\text { - A professora } \\
\text { apresentou explicações } \\
\text { sobre os entendimentos } \\
\text { dos estudantes. }\end{array}$ & $\begin{array}{l}\text { - Durante todo o } \\
\text { momento em que a } \\
\text { professora falou, ela } \\
\text { caminhou entre } \\
\text { os grupos; } \\
\text { - Risadas no } \\
\text { momento em que } \\
\text { uma estudante falava } \\
\text { da sua experiência } \\
\text { com a agricultura; } \\
\text { - A professora não } \\
\text { problematizou as } \\
\text { falas daqueles que } \\
\text { falaram e centrou } \\
\text { sua atenção apenas } \\
\text { em dois grupos } \\
\text { específicos; } \\
\text { - Muitos grupos } \\
\text { ficaram calados; } \\
\text { - A professora } \\
\text { contextualizou a } \\
\text { temática dentro da } \\
\text { história da ciência, } \\
\text { quando indicou } \\
\text { que Linneaus } \\
\text { foi o criador da } \\
\text { nomenclatura } \\
\text { binomial e da } \\
\text { classificação } \\
\text { científica. }\end{array}$ \\
\hline $14 \min 52 \mathrm{~s}$ & $\begin{array}{l}\text { - Apresentação } \\
\text { de slides e } \\
\text { discussão. } \\
\text { - Episódio } \\
\text { 2: Tentando } \\
\text { resolver uma } \\
\text { questão: Por que } \\
\text { o inimigo natural } \\
\text { não come } \\
\text { a lagarta? }\end{array}$ & $\begin{array}{l}\text { - Morfologias: } \\
\text { da Mariposa; } \\
\text { da lagarta e do } \\
\text { Trichogramma } \\
\text { spp. (inimigigo } \\
\text { naturall; } \\
\text { Consequência de } \\
\text { um milho atacado } \\
\text { pela lagarta; A } \\
\text { importância da } \\
\text { não utilização } \\
\text { do veneno para } \\
\text { o combate das } \\
\text { pragas agrícolas. }\end{array}$ & $\begin{array}{c}\text { - Os estudantes } \\
\text { escutaram a } \\
\text { apresentação } \\
\text { da professora; } \\
\text { - A professora } \\
\text { apresentou slides } \\
\text { com ilustrações dos } \\
\text { personagens do texto } \\
\text { (material didático) } \\
\text { - Alguns estudantes } \\
\text { lançaram } \\
\text { questionamentos sobre } \\
\text { a apresentação } \\
\text { da professora. }\end{array}$ & $\begin{array}{l}\text { - Uma estudante teve } \\
\text { uma dúvida sobre o } \\
\text { motivo de o inimigo } \\
\text { natural comer } \\
\text { os ovos e não a } \\
\text { lagarta. A professora } \\
\text { não instigou seu } \\
\text { pensamento até } \\
\text { a elaboração de } \\
\text { uma resposta que } \\
\text { estabelecesse } \\
\text { relações com os } \\
\text { conhecimentos } \\
\text { tradicionais. } \\
\text { Contrariamente, } \\
\text { apresentou uma } \\
\text { resposta pronta } \\
\text { (científica); } \\
\text { - A professora } \\
\text { interrompeu as } \\
\text { falas de alguns } \\
\text { estudantes, ao } \\
\text { invés de prová-las e } \\
\text { problematizá-las; } \\
\text { - Muitos grupos } \\
\text { ficaram calados. }\end{array}$ \\
\hline
\end{tabular}

Fonte: Resultado da pesquisa. 
Quadro 3 - Mapa dos eventos ocorridos nas duas últimas aulas da professora coautorano dia 30 de setembro de 2009, com duração de $41 \mathrm{~min} 30$ s.

\begin{tabular}{|c|c|c|c|c|}
\hline Duração & Atividades & $\begin{array}{c}\text { Temas } \\
\text { abordados }\end{array}$ & $\begin{array}{c}\text { Ações dos } \\
\text { participantes }\end{array}$ & Comentários \\
\hline $8 \mathrm{~min} 26 \mathrm{~s}$ & $\begin{array}{l}\text { - Revisão dos } \\
\text { conteúdos e } \\
\text { das atividades } \\
\text { realizadas nas aulas } \\
\text { anteriores; } \\
\text { - Apresentação e } \\
\text { orientação para o } \\
\text { desenvolvimento } \\
\text { das atividades do dia } \\
\text { (jogo: uma questão } \\
\text { de sobrevivência). }\end{array}$ & & $\begin{array}{l}\text { - Os estudantes } \\
\text { sentaram-se } \\
\text { organizados de } \\
\text { acordo com os } \\
\text { grupos das aulas } \\
\text { anteriores; } \\
\text { - A professora } \\
\text { apresentou os } \\
\text { objetivos das aulas } \\
\text { e das filmagens; }\end{array}$ & $\begin{array}{l}\text { - Intenso barulho } \\
\text { na sala de aula; } \\
\text { - A professora } \\
\text { explicou as regras } \\
\text { quando ainda } \\
\text { estava distribuindo } \\
\text { o jogo entre } \\
\text { os grupos. }\end{array}$ \\
\hline $18 \mathrm{~min} 20 \mathrm{~s}$ & $\begin{array}{l}\text { - Desenvolvimento } \\
\text { do jogo: uma } \\
\text { questão de } \\
\text { sobrevivência. }\end{array}$ & & $\begin{array}{l}\text { - Os estudantes } \\
\text { jogaram em grupo; } \\
\text { - A professora } \\
\text { caminhou entre os } \\
\text { grupos esclarecendo } \\
\text { possíveis dúvidas. }\end{array}$ & $\begin{array}{l}\text { - Os estudantes } \\
\text { conversaram } \\
\text { muito entre si, } \\
\text { demonstrando } \\
\text { atenção para } \\
\text { solucionar os } \\
\text { problemas } \\
\text { encontrados } \\
\text { no jogo; } \\
\text { - Não foi possível } \\
\text { captar as falas } \\
\text { individuais de todos } \\
\text { os estudantes por } \\
\text { conta do barulho } \\
\text { que fizeram ao } \\
\text { conversarem } \\
\text { dentro dos seus } \\
\text { grupos. }\end{array}$ \\
\hline
\end{tabular}




\begin{tabular}{|c|c|c|c|c|}
\hline Duração & Atividades & $\begin{array}{c}\text { Temas } \\
\text { abordados }\end{array}$ & $\begin{array}{c}\text { Ações dos } \\
\text { participantes }\end{array}$ & Comentários \\
\hline $14 \min 44 \mathrm{~s}$ & $\begin{array}{l}\text { - Discussão sobre } \\
\text { o jogo. } \\
\text { - Episódio 3: } \\
\text { Tentando resolver } \\
\text { uma questão: é } \\
\text { uma ação positiva a } \\
\text { utilização do veneno } \\
\text { no combate das } \\
\text { pragas agrícolas? }\end{array}$ & $\begin{array}{l}\text { - Plantação e } \\
\text { sua relação } \\
\text { com a chuva; } \\
\text { Irrigação } \\
\text { como meio } \\
\text { alternativo } \\
\text { para o cultivo } \\
\text { das plantas; } \\
\text { Aquecimento } \\
\text { global; Pragas } \\
\text { agrícolas, } \\
\text { controle } \\
\text { químico e } \\
\text { biológico. }\end{array}$ & $\begin{array}{c}\text { - A professora lança } \\
\text { questões sobre o } \\
\text { desenvolvimento } \\
\text { do jogo; } \\
\text { - Os estudantes } \\
\text { apresentaram } \\
\text { respostas aos } \\
\text { questionamentos } \\
\text { da professora. }\end{array}$ & $\begin{array}{l}\text { - A professora } \\
\text { interrompeu o jogo } \\
\text { antes que todos } \\
\text { os estudantes } \\
\text { tivessem } \\
\text { terminado } \\
\text { de jogar; } \\
\text { - Barulho na } \\
\text { sala de aula; } \\
\text { - A professora } \\
\text { percebeu um erro } \\
\text { na numeração das } \\
\text { casas do jogo e } \\
\text { tece explicações; } \\
\text { - A professora } \\
\text { deu voz à sala } \\
\text { como um todo, } \\
\text { mas não explorou } \\
\text { os raciocínios de } \\
\text { cada estudante, } \\
\text { buscando } \\
\text { evidenciar a } \\
\text { origem da sua } \\
\text { ideia, dentro do seu } \\
\text { meio cultural; } \\
\text { - A maioria } \\
\text { dos estudantes } \\
\text { conversou entre } \\
\text { si, mas não } \\
\text { se dirigiram à } \\
\text { professora; } \\
\text { - A professora } \\
\text { encerrou a aula } \\
\text { falando dos } \\
\text { produtos químicos, } \\
\text { mas não deu um } \\
\text { fechamento de } \\
\text { acordo com os } \\
\text { seus objetivos } \\
\text { propostos. }\end{array}$ \\
\hline
\end{tabular}

Fonte: Resultado da pesquisa.

O episódio selecionado para análise das abordagens feitas pela professora durante as suas intervenções pedagógicas foi o de número 2 (Ver Quadro 2). Tal seleção se deu por acreditar que o mesmo constitui o melhor conjunto de enunciados das interações entre a professora e os estudantes nas salas de aula de Biologia sob estudo. Este episódio está destacado no mapa dos eventos ocorridos nas duas primeiras aulas da professora (Quadro 2) e será a seguir descrito no Quadro 4 para posterior análise (MORTIMER; SCOT'T, 2002). 
Quadro 4 - Episódio selecionado para análise: Por que 0 inimigo natural come os ovos e não a lagarta?

1. ESTUDANTE 5: ô pró....por que ela não come a lagarta?

2. PROFESSORA: porque é assim... tem coisas que eu não consigo ser $100 \% \ldots$ mas eu vou tentar dar uma explicação... os animais eles tem um hábito alimentar... certo? o estudo que se baseou pra esse animal... ele como inimigo natural... observou que cultivando eles... colocando junto da plantação ele ia comer os ovos... acredito eu que ele não tenha... não seria tamanho... mas condi... esse inseto ele teria um hábito alimentar menor... exatamente por que ele não destrói a lagarta... eu não sei... mas a gente pode... na próxima aula eu posso trazer pra vocês porque que ele não come... ou talvez essa pergunta...

3. ESTUDANTE 3: ô professora...

4. PROFESSORA: ((A professora fez sinal com as mãos pedindo)) espera aí... rapidinho gente... só pra esclarecer... teve um comercial... bem legal que passou recentemente na Tv Cultura... até hoje os biólogos querem entender porque as aves voam... até hoje os nutricionistas querem entender o porquê que a galinha... não, melhor... se o colesterol é bom... não... se o ovo tem ou não tem colesterol... aí no final ele diz que não são as respostas que movem o mundo...

5. ESTUDANTE 4: são as perguntas...

6. PROFESSORA: exatamente... são as perguntas... as perguntas é que dão direcionamento das situações...

7. ESTUDANTE 3: assim... porque ele só faz comer os ovos da lagarta... mas em compensação é a lagarta que estava comendo a folha? se a lagarta que tá comendo a folha... e... se a lagarta continuar produzindo os ovos?

8. PROFESSORA: ((A professora se afastou da estudante e se dirigiu aos demais dizendo)) vamos lá... vamos ver aí... se ele tiver lá na plantação... lá em...

9. ESTUDANTE 2: ((A professora faz um sinal para uma estudante e ela completa)) lá em Jaíba...

10. PROFESSORA: lá em Jaíba... vai virar lagarta?

\section{TODOS OS ESTUDANTES: [não...]}

12. PROFESSORA: não... porque vai eliminar antes do desenvolvimento... é claro que dependendo da quantidade... e aí vai ver aquela coisa do equilíbrio e do desequilíbrio... se houver uma quantidade muito grande de ovos... por mais que seja guloso... ele não dá conta... então... a quantidade de lagarta... a população de lagarta vai ficar lá crescendo... então... se eu tenho ele em equilíbrio... se eu tenho ele em quantidade que dê condições pra que a lagarta não se de... não acabe com a plantação... ele aí ajuda a resolver o controle biológico... o último... o penúltimo slide... então... o que é que a gente tem aí nessa figura?

13. TODOS OS ESTUDANTES: [a lagarta na plantação do milho...]

14. PROFESSORA: A lagarta do milho... ela começa assim... 
15. ESTUDANTE 5: ela entra no milho... ela perfura o milho pra devorar o alimento que tá dentro...

16. PROFESSORA: ela destrói o milho e aí o milho não serve para o consumo...

17. ESTUDANTE 3: na plantação da minha mãe é diferente... tem os porcos e sabe o que é que minha avó faz? ela bota uma proteção no pescoço pra não pular a cerca.

18. PROFESSORA: ((Neste momento todos começaram a rir e a professora disse)) é... mais aí são estratégia que envolve o porco que a gente chama de pecuária... é um preço que se paga... ((Voltando-se para a lousa, a professora continuou a sua apresentação)) vamo lá... a última apresentação... um mosaico... digamos assim... é uma edição... eu fiz uma edição no photoshop e aí... lembra? a lagartinha gorduchinha... e, aí... quem é aquele da ponta de lá?

19. TODOS OS ESTUDANTES: llOs estudantes observando atentamente a imagem responderam]) [o inimigo natural...]

20. PROFESSORA: o inimigo natural... a lagartinha... a outra fase... que é mariposa...

21. ESTUDANTE 5: (la estudante interrompeu a fala da professora dizendo)) e ele destruiu o lado do milho... coitado do milho...

22. PROFESSORA: então olha só... e agora... finalmente... o resumo do que vocês disseram... fase da lagarta... momento em que ela se encontra como praga... fase da lagarta que tá passando... que não é a lagarta é mariposa e o inimigo natural... então... a gente conseguiu hoje dar seguimento a nossa proposta de trabalho que foi ler o texto, discutir um pouquinho... conversar e na próxima aula a gente continua a proposta de... é uma outra atividade de proposta... tá? é um jogo... bom gente... tem alguma dúvida?

23. TODOS OS ESTUDANTES: [não...]

Fonte: Resultado da pesquisa.

O episódio selecionado se insere logo após a leitura e discussão do texto elaborado pela professora (recurso didático). Especificamente, durante a sua apresentação de alguns slides contendo imagens das lagartas da espécie Spodoptera frugiperda. A intenção da professora com essa apresentação foi mostrar imagens ilustrativas do processo reprodutivo aos estudantes, da transformação da lagarta em borboleta, do inimigo natural e o seu controle biológico pelo Trichogramma spp. Também foi intenção da professora mostrar imagens de um milho sendo atacado pela lagarta e a importância da não utilização do veneno para o combate das pragas agrícolas.

Enquanto a professora apresentava os slides, a Estudante 5 lançou o seguinte questionamento: "Ô pró...por que ela não come a lagarta?". Na tentativa de apresentar uma resposta para a estudante, a professora disse:

... tem coisas que eu não consigo ser $100 \%$... mas eu vou tentar dar uma explicação... os animais eles tem um hábito alimentar... certo? o estudo que se baseou pra esse animal... ele como inimigo natural... observou que cultivando eles... colocando junto da plantação ele ia comer os ovos... acredito eu que ele não tenha... não seria tamanho... mas condi... esse inseto ele teria um hábito alimentar menor... exatamente por que ele não destrói a lagarta... eu não sei... ... mas a gente pode... na próxima aula eu posso trazer pra vocês porque que ele não come... ou talvez essa pergunta... (professora coautora). 
Como é possível notar na sua fala acima, a professora mostrou-se insegura ao tentar responder à pergunta da estudante 5 e, além disto, tentou uma resposta completa, com base nos argumentos científicos, sem qualquer relação com os conhecimentos prévios dos indivíduos que ali estavam presentes. No lugar disto, ela poderia ter explorado a possibilidade de resposta pela própria estudante e, do mesmo modo, ter incentivado a participação dos demais.

Seguidamente a fala da professora, a Estudante 3 tentou expressar uma ideia dizendo: “... ô pró...", porém, a sua fala foi interrompida pela professora, quando apresentou argumentos que sugerem uma tentativa de justificativa de uma possível falta de precisão na sua resposta dada anteriormente. No trecho que segue é possível perceber esta tentativa de justificativa:

... espera aí... rapidinho gente... só pra esclarecer... teve um comercial... bem legal que passou recentemente na Tv Cultura... até hoje os biólogos querem entender porque as aves voam... até hoje os nutricionistas querem entender o porque que a galinha... não, melhor... se o colesterol é bom... não... se o ovo tem ou não tem colesterol... aí no final ele diz que não são as respostas que movem o mundo... (professora coautora).

$\mathrm{Na}$ fala da professora acima também é possível observar uma tentativa de argumentação de que os estudos científicos não têm respostas para todos os questionamentos da humanidade, contudo, são motivados constantemente por novos questionamentos. Isto parece ter sido percebido por alguns dos estudantes e serve como exemplo o fato de que a Estudante 4 completou a fala da professora dizendo que "... são as perguntas" que movem o mundo. A estudante 4 parece ter entendido que os questionamentos são de extrema importância para geração de novos conhecimentos no contexto das atividades científicas, todavia, isto não foi explorado pela professora.

De acordo com Gil-Pérez et al. (2002), é necessário trabalhar concepções adequadas sobre a natureza das investigações científicas com os estudantes. No caso específico da situação acima apresentada, seria interessante que a professora trabalhasse concepções de que a ciência, dentre outras caracterísiticas, não raciocina em termos de certezas absolutas, prontas e acabadas, mas, sim, em termos de questionamentos e hipóteses constantes, que deverão ser colocadas à prova de um referencial teórico (GIL-PÉREZ et al., 2002).

Dando continuidade às interações, a Estudante 3 interrompeu a conversa entre a professora e a Estudante 4 e questionou o que aconteceria com uma lagarta que estivesse agredindo as folhas da planta. Na fala da Estudante 3: “... assim... porque ele só faz comer os ovos da lagarta... mas em compensação e a lagarta que estava comendo a folha? se a lagarta que tá comendo a folha... e... se a lagarta continuar produzindo os ovos?". A professora repassou o questionamento da Estudante 4 aos demais sem nenhuma problematização e clareza: "vamos lá... vamos ver aí... se ele tiver lá na plantação... lá em...". Todos permaneceram calados até que a estudante 2 tentou falar: “... lá em Jaíba...”. Neste momento, foi interessante notar como a professora deteve a fala desta estudante lançando o seguinte questionamento para toda a classe: “... lá em Jaíba... vai virar lagarta?”. Os estudantes responderam que "não". A professora não propiciou oportunidade e suporte para que os estudantes produzissem significados no espaço social da sala de aula, visto que 
não problematizou o questionamento da Estudante 3 e a resposta dada pelos seus colegas e, ainda, interrompeu a fala da Estudante 2.

A ausência de oportunidades dadas pela professora na sala de aula para produção de significados também ficou evidente na sua fala que seguiu ao questionamento da estudante 2 , como pode ser observado na transcrição abaixo:

... não... porque vai eliminar antes do desenvolvimento... é claro que dependendo da quantidade... e aí vai ver aquela coisa do equilíbrio e do desequilíbrio... se houver uma quantidade muito grande de ovos... por mais que seja guloso... ele não dá conta... então... a quantidade de lagarta... a população de lagarta vai ficar lá crescendo... então... se eu tenho ele em equilíbrio... se eu tenho ele em quantidade que dê condições pra que a lagarta não se de... não acabe com a plantação... ele aí ajuda a resolver o controle biológico... (professora).

Como é possível notar, a professora fez uma pergunta e seguidamente emitiu uma resposta, sem instigar e aguardar a participação de todos os estudantes. Após isto, mudou bruscamente o foco das discussões do momento, apresentando slides contendo imagens dos personagens do texto (material didático por ela produzido). Neste momento, ela questionou a observação de todos aos slides por ela apresentados e eles responderam que seria "... a lagarta da plantação do milho...". A professora confirmou esta resposta e sem tentativas de estabelecimento de diálogos. Ela poderia, por exemplo, ter questionado aos estudantes quais as razões pelas quais eles chegaram a tal conclusão.

A perda de oportunidade para o estabelecimento de diálogos foi repetida logo em seguida da situação acima, quando a Estudante 5 disse “... ela entra no milho... ela perfura o milho pra devorar o alimento que tá dentro..." e a professora apenas confirmou a fala desta estudante dizendo: “... ela destrói o milho e ai o milho não serve para o consumo...". Para Mercer e Howe (2012), é necessário que os professores instiguem as falas dos estudantes no lugar de apenas apresentar respostas e esperar assimilações, pois isto contribui para o enriquecimento intelectual. Seria preciso que a professora problematizasse as falas dos estudantes com questões que objetivassem o estabelecimento de relações dialógicas entre o que ela estava ensinando e os conhecimentos prévios acerca do assunto. A professora poderia ter questionado, por exemplo, como a estudante conhece o fato de que a lagarta perfura o milho para sua alimentação. Poderia buscar compreender se seus conhecimentos são empíricos, resultantes das suas relações com o trabalho agrícola e, deste modo, abrir espaço para o estabelecimento de relações de semelhanças e/ ou de diferenças entre os conhecimentos tradicionais e os científicos no campo da biologia escolar (BAPTISTA, 2007).

Outro momento oportuno para o diálogo que não foi aproveitado ocorreu quando a Estudante 5 disse: “... na plantação da minha mãe é diferente... tem os porcos e sabe o que é que minha avó faz? ela bota uma proteção no pescoço pra não pular a cerca". Dito isto, os demais estudantes começaram a rir e a professora argumentou: "... é... mais aí são estratégia que envolve o porco que a gente chama de pecuária... é um preço que se paga...”.A professora voltou-se então para a lousa e deu continuidade a apresentação dizendo:““... vamo lá... a última apresentação... um mosaico... digamos assim... é uma edição... eu fiz uma edição no photoshop e aí... lembra? a lagartinha gorduchinha... e, aí... 
quem é aquele da ponta de lá?". Os estudantes responderam à pergunta dizendo ser “...o inimigo natural..." presente no slide e a Professora confirmou esta resposta dizendo: “... o inimigo natural... a lagartinha... a outra fase... que é mariposa...". Por não ter explorado a fala da Estudante 5 e ter dado seguimento imediato a apresentação dos slides com questionamentos que indicaram uma tentativa de finalização da aula, é possível inferir que a professora estava mais preocupada com o cumprimento do conteúdo a ser trabalhado do que com a ampliação dos conhecimentos dos estudantes.

De acordo com Maldaner et al. (2006) a excessiva preocupação com cumprimento de conteúdos pode prejudicar a preparação dos jovens para a participação no contexto social com vistas a uma melhor qualidade de vida. É possível que a estudante 5 quisesse apenas explicar a existência de uma outra forma de ataque às plantações de milho e quais medidas são utilizadas para o combate. A professora poderia ter explorado mais a fala da Estudante 5, ainda que sugerisse a abordagem de um conteúdo diferente do que estava sendo explicado, pois isto poderia contribuir para que ela ampliasse as suas concepções sobre agricultura e controle biológico, podendo atuar neste sentido no meio social onde vive.

$\mathrm{O}$ riso por parte dos estudantes no momento da fala da Estudante 5 pode ter significado discriminação sobre a sua origem e forma de expressão dos seus conhecimentos prévios. Segundo Johnson (1997), a discriminação é fruto de preconceitos, que significam conceitos antecipados por parte de um indivíduo ou grupo sobre algo ou alguém, podendo ser considerado favorável ou desfavorável. Para Grupioni (1995), a discriminação vem a ser o tratamento desfavorável dado a certa categoria de pessoas ou grupos, que pode ser exercido de forma individual ou coletiva. Vale lembrar que o ser humano se forma como sujeito nas suas relações sociais e culturais (VYGOTSKY, 1979). Isto significa dizer que os meios sociais nos quais os sujeitos transitam podem afetar de forma positiva ou negativa nos seus comportamentos. Sendo assim, a professora poderia ter considerado que a escola, como espaço no qual transitam várias culturas, deve incentivar o respeito e a tolerância dos elementos culturais adquiridos pelos indivíduos através das suas histórias de vida. Ela poderia ter questionado as razões que levaram os demais estudantes ao riso e, de forma paralela, incentivado a fala da Estudante 5 para que conseguisse participar de forma efetiva na aula, emitindo suas opiniões. Como bem afirma Candau (2002), a redução da discriminação representa uma das dimensões que caracterizam a educação sensível à diversidade cultural.

Por fim, a estudante 5 interrompeu a fala da professora dizendo: “...e ele destruiu o lado do milho... coitado do milho...".Sobre esta fala, a professora nada comentou e encerrou a aula dizendo:

... então olha só... e agora... finalmente... o resumo do que vocês disseram... fase da lagarta... momento em que ela se encontra como praga... fase da lagarta que tá passando... que não é a lagarta é mariposa e o inimigo natural... então... a gente conseguiu hoje dar seguimento a nossa proposta de trabalho que foi ler o texto, discutir um pouquinho... conversar e na próxima aula a gente continua a proposta de... é uma outra atividade de proposta... tá? é um jogo... bom gente... tem alguma dúvida? (Professora). 
Como é possível observar até aqui, a professora coautorarealizou uma abordagem comunicativa do tipo interativa de autoridade, visto que ela conduziu os estudantes a respostas sempre com o intuito de alcançar pontos de vistas específicos dentro da biologia sobre as pragas agrícolas. Ou seja, a professora não explorou as falas dos estudantes com questionamentos para que expressassem os seus próprios saberes culturais, conforme prevê a dimensão dialógica proposta por Mortimer e Scott (2002). Além disto, ela interrompeu a fala de alguns estudantes, deixando outros calados, sem nenhuma atenção e, de igual forma, finalizou a sequência didática fechando a possibilidade de que perguntas fossem realizadas pelos estudantes.

\section{CONCLUSÕES}

Com base nas discussões anteriormente apresentadas, é possível inferir que a professora não conseguiu dialogar com os estudantes, embora ela tenha, na época em que o estudo foi desenvolvido, acabado de participar de um curso de formação continuada de professores que teve por finalidade específica preparála para o diálogo intercultural, partindo de abordagens teóricas e práticas que envolveram questões epistemológicas e a construção de um recurso e sequência didática intercultural.

O fato de a professora não ter conseguido uma abordagem comunicativa do tipo dialógica, mas sim de autoridade, pode ter relações com a sua formação, desde a sua graduação até a própria docência na escola, que tem relação com a cultura escolar.É possível que a cultura escolar da qual a professora faz parte tenha uma visão cientificista, dando prioridade a uma prática pedagógica que tem por base a ideia de ciência como a única e legítima fonte de produção de conhecimentos válidos e que, portanto, devem considerar os conhecimentos prévios dos estudantes com o objetivo de sobrepô-los com ideias científicas. Tal formação pedagógica é difícil de ser modificada tão rapidamente após um curso de formação continuada, como questionada no presente estudo.

O que é possível inferir sobre a prática pedagógica da professora logo após a sua participação no curso é que ela refletiu sobre a maneira como ensina, tendo em mente que o diálogo intercultural é importante para que a educação em biologia tenha significações para os estudantes. Isto pode ser comprovado se considerada a fala da professora durante a apresentação na sala de aula do curso na UEFS das gravações em vídeo das suas aulas, a qual indica o seu reconhecimento de não ter realizado uma relação dialógica nas suas aulas e que necessita de tempo mais prolongado para que mude a sua prática neste sentido, como é possível constatar na transcrição a seguir:

\footnotetext{
Assim, permitir a fala eu permiti, só que eu poderia ter sido melhor. Eles poderiam ter falado mais, argumentado se a problematização fosse maior. Eu acredito que as coisas não acontecem de uma hora pra outra. Então, eu acredito que a problematização dessa importância que é o conhecimento cultural do estudante, ela não vai ser como uma luz, assim, automática. Não que eu não queira. Eu sei que isso não foi absolutamente garantido porque nas entrelinhas depois você consegue fazer uma leitura do que foi a sua aula. Todo professor sabe disso.
} 


\begin{abstract}
Mas não é que eu provoquei a situação pra que ela não acontecesse. Não. Algumas falas eu problematizei, quer dizer, não sei, algumas falas, mas eu acho que poderia ter sido muito melhor! Eu poderia ter explorado, tendo em vista que eles detinham as informações, garantido nas entrevistas. Então eu vi que eles já traziam um contexto das situações que eles viviam e a aula foi elaborada a partir do que eles sabiam, do que eles tinham como informações, e na sala eles foram demarcando em alguns momentos (Professora coautora).
\end{abstract}

Além disto, o fato de a professora ter conseguido questionar os estudantes, tentando envolvê-los na sua aula, no lugar de simplesmente apresentar-lhes os conteúdos científicos, pode ser um grande indicativo de que ela dará continuidade à reflexão, podendo investigar novos caminhos para mudanças no ensino de Ciências que respeita e considera a diversidade cultural.

Entende-se que quanto mais é exercitada, mais formativa se torna a investigação e a reflexão. Sendo assim, torna-se necessária a geração de momentos que sejam mais prolongados durante os cursos de formação de professores. Para isto, é preciso que esses cursos aconteçam dentro dos espaços físicos das escolas onde atuam os professores participantes, pois isto poderá garantir-lhes experiências mais efetivas e contextualizadas com as realidades de ensino que vivenciam cotidianamente. Além disso, poderá estabelecer uma aproximação mais estreita entre universidade e escola, entre os saberes acadêmicos, os saberes científicos escolares e os saberes locais, inerentes aos universos socioculturais dos estudantes. Sobre este último é importante destacar que a sua consideração nos momentos de diálogos muito pode contribuir para a valorização e respeito das identidades culturais desses sujeitos, que poderão sentir-se motivados à aprendizagem de conceitos, teorias e modelos científicos trabalhados no ensino.

Como consequência, os professores ampliarão as suas investigações e reflexões, não somente sobre as suas próprias práticas pedagógicas, mas, também, dos seus pares, podendo contribuir de maneira colaborativa para que mudanças efetivas ocorram. De acordo com Mizukami et al. (2002), aprender a ensinar e se tornar professor são processos de longa duração, e não eventos isolados.

\title{
REFERÊNCIAS
}

AIKENHEAD, G. S. Science communication with the public: a cross-cultural event. In: BRYANT, C.; GORE, M.; STOCKLMAYER, S. (Eds.). Science communication in theory and practice. Amsterdam: Kluwer, p. 23-45, 2001.

ALBUQUERQUE, U. P. de. Etnobiologia e biodiversidade. Série: Estudos e debates. Recife: NEPEEA/Sociedade Brasileira de Etnobiologia e Etnoecologia, 2005.

AMARAL, E. M. R.; MORTIMER, E. F. Uma metodologia para análise da dinâmica entre zonas de um perfil conceitual no discurso da sala de aula. In: SANTOS, F. M. T. dos; GRECA, I. M. (org.) A pesquisa em Ensino de Ciências no Brasil e suas metodologias. Ijuí: Editora Unijuí, p. 239-296, 2006.

APOSTOLOU, A.; KOULAIDIS, V. Epistemology and science education: a study of epistemological views of teachers. Research in Science \& Technological Education, v. 28, n. 2, p. 149-166, 2010.

BAPTISTA, G. C. S. A Contribuição da etnobiologia para o ensino e a aprendizagem de Ciências: estudo de caso em uma escola pública do Estado da Bahia. Dissertação de mestrado, Programa de Pós-graduação em Ensino, Filosofia e História das Ciências, Salvador: Universidade Federal da Bahia - Universidade Estadual de Feira de Santana, 2007. 
BCEGG - Blog do Colegiado Escolar Gastão Guimarães. Disponível em: http:/ / colegiadogastao. blogspot.com. Acesso em: 07 ago. 2010.

BELL, R. L.; LEDERMAN, N. G. Understandings of the nature of science and decision making on science and technology based issues. Science Education, New York, v. 87, n. 3, p. 352-377, 2003.

BRASIL. Ministério da Saúde. Conselho Nacional de Saúde. Comissão Nacional de Ética em Pesquisa. Normas para pesquisa envolvendo seres humanos. $2^{\mathrm{a}}$ ed., Brasília: Ministério da Saúde, 2003.

CARVALHO, A. M. P. de. A pesquisa no ensino, sobre o ensino e sobre a reflexão dos professores sobre seus ensinos. Educação \& Pesquisa, v. 28, n. 2, p. 57-67, 2002.

CARVALHO, A. M. P. Uma metodologia de pesquisa para estudar os processos de ensino e aprendizagem em salas de aula. In: SANTOS, F. M. T. dos; GRECA, I. M. (org.) A pesquisa em ensino de ciências no Brasil e suas metodologias. Ijuí: Editora Unijuí, p.13-48, 2006.

CANDAU, V. M. Sociedade, cotidiano escolar e cultura(s): uma aproximação. Educação \& Sociedade, Ano XXIII, n. 79, p. 125-161, 2002.

COBERN, W. W. Apples and oranges: a rejoinder to Smith and Siegel. Science Education, v. 13, n. 6, p. 583-589, 2004.

COBERN, W. W.; LOVING, C. C. Defining science in a multicultural world: Implications for science education. Science Education, v. 85, p. 50-67, 2001.

GIL-PÉREZ, D.; MONTORO, I. F.; ALÍS, J. C.; CACHAPUZ, A.; PRAIA, J. Para uma imagem não deformada do trabalho científico. Ciência \& Educação, v. 7, n. 2, p. 125-153, 2001.

GRUPIONI, L. D. B. Livros didáticos e fontes de informações sobre as sociedades indígenas no Brasil. In: GRUPIONI, L. D. B.; SILVA, A. L. da. A temática indígena na escola: novos subsídios para professores de $1^{\circ}$ e $2^{\circ}$ graus.Brasília: MEC/MARI/UNESCO, p. 481-525, 1995.

JOHNSON, A. G. Dicionário de sociologia: guia prático da linguagem sociológica. Rio de Janeiro: Jorge Zahar, 1997.

LEDERMAN, N. G. Students' and teachers' conceptions of the nature of science: A review of the research. Journal of Research in Science Teaching, 29, p. 331-359, 1992.

MALDANER, O. A. A formação inicial e continuada de professores de química. Ijuí: Editora Unijuí, 2000.

MALDANER, O. A.; ZANON, L. B.; AUTH, M. A. Pesquisa sobre educação em ciências e formação de professores. In: SANTOS, F. M. T. dos \& GRECA, I. M. A pesquisa em ensino de ciências no Brasil e suas metodologias. Ijuí: Editora Unijuí, p.49-88, 2006.

MARTINS, H. T. de S. Metodologia qualitativa de pesquisa. Educação e Pesquisa, v. 30, n. 2, p. 289-300, 2004.

MENDONÇA, P. C. C.; JUSTI, R. da S. Ensino-Aprendizagem de Ciências e Argumentação: Discussões e Questões Atuais. Revista Brasileira de Pesquisa em Educação em Ciências, v. 13, n. 1, p. 187-216, 2013.

MERCER, N.; HOWE, C. Explaining the dialogic processes of teaching and learning: The value and potential of sociocultural theory. Learning, Culture and Social Interaction. v. 1, n. 1, p. 12-21, 2012. MIZUKAMI, M. G. N.; REALI, A. M. M. R.; REYES, C. R.; MARTUCCI, E. M.; LIMA, E. F; TANCREDI, R. M. S. P.; MELLO, R. R. Escola e aprendizagem da docência: processos de investigação e formação. São Carlos: Editora UFSCar, 2002.

MORTIMER, E. F.; SCOTT, P. Atividade discursiva nas salas de aula de ciências: uma ferramenta sociocultural para analisar e planejar o ensino. Investigações em Ensino de Ciências, v.7, n. 3, p. 283-306, 2002.

NÓVOA, A. Os professores e a sua formação. $2^{\mathrm{a}}$ ed. Lisboa: Instituto Inovação Educacional, 1992.

PARRILLA, A.; DANIELS, H. Criação e desenvolvimento de grupos de apoio para professores. São Paulo: Loyola, 2004. 
SANTOS, B. de S.; MENESES, M. P. (org.). Epistemologias do Sul. São Paulo; Editora Cortez. 2010.

SCHÖN, D. A. Formar professores como profissionais reflexivos. In: NÓVOA, A. (coord.). Os professores e a sua formação. Lisboa: Dom Quixote,p. 77-91, 1992.

SILVA, P. S. A. da; CHAVES, S. N. Epistemologia, ética e política na formação de professores de ciências. Ensaio: Pesquisa em Educação em Ciências, v.11, n. 2, p. 230-244, 2009.

STAKE, R. E.The art of case study research. Thousand Oaks, California: Sage, 1995.

TARDIF, M. Saberes docentes e formação profissional. Petrópolis: Vozes, 2002.

TURGUT, H. The Context of demarcation in nature of science teaching: the case of astrology.

Science \& Education, v. 20, n. 5-6, p. 491-515, 2011.

VILELA-RIBEIRO, E. B.; BENITE, A. M. C. Concepções sobre natureza da ciência e ensino de ciências: um estudo das interações discursivas em um Núcleo de Pesquisa em Ensino de Ciências. Revista Brasileira de Pesquisa em Educação em Ciências, v. 9, n. 1, p. 1-21, 2009.

VYGOTSKY, L. S. Pensamento e linguagem (Tradução: M. Resende). Lisboa: Antídoto, 1979.

YIN, R. K. Case Study Research: Design and Methods. $3^{\text {a }}$ ed. Londres: Sage publications, 2003.

\section{NOTAS}

${ }^{1}$ Segundo Cobern (2004), a compreensão significa entendimento e é diferente da apreensão, que significa convicção. De acordo com este autor, compreender uma proposição significa ter domínio sobre ela, diferentemente da apreensão, que significa assumir uma noção como válida ou verdadeira, emitir um julgamento de verdade sobre uma proposição.

${ }^{2}$ A etnobiologia é o estudo dos conhecimentos e das conceituações desenvolvidas por qualquer cultura sobre os seres vivos e os fenômenos biológicos (ALBUQUERQUE, 2005), fazendo uso de procedimentos etnográficos para o alcance desta finalidade como, por exemplo, observação direta e participante, entrevistas, filmagens, desenhos e fotografias, entre outras.

\section{Submetido em 07/09/2016}

Aprovado em 15/09/2017

\section{Contato:}

Universidade Estadual de Feira de Santana,

Departamento de Educação

Av. Transnordestina, S/N, Novo Horizonte,

CEP 44.036-900 - Feira de Santana, BA - Brasil 